\title{
ROLE OF GOVERNMENTAL AND NON-GOVERNMENTAL ORGANIZATIONS IN MITIGATION OF STIGMA AND DISCRIMINATION AMONG HIV/AIDS PERSONS IN KIBERA, KENYA
}

\author{
Margaret A. Odindo ${ }^{1}$ and Mutuku A. Mwanthi ${ }^{2}$
}

Abstract

\begin{abstract}
Objective: This study assessed the role of governmental and non-governmental organizations in mitigation of stigma and discrimination among people infected and affected by HIV/AIDS in informal settlements of Kibera.

Methods: This was a descriptive cross-sectional study and used a multi stage stratified sampling method. The study was conducted in Kibera, an informal settlement with a population of over one million people which makes it the largest slum not only in Kenya but in sub-Saharan Africa. The study targeted infected individuals, non-infected community members, managers of the organizations implementing HIV/AIDS programmes and service providers. In the process 1331 households were interviewed using qualitative and quantitative data collection instruments. Statistical Package for Social Sciences (SPSS) and Nudist 4 packages were used to analyze the quantitative and qualitative data respectively.

Results: More than $61 \%$ of the respondents had patients in their households. Fifty five percent $(55 \%)$ of the households received assistance from governmental and non-governmental organizations in taking care of the sick. Services provided included awareness, outreach, counseling, testing, treatment, advocacy, home based care, assistance to the orphans and legal issues. About $90 \%$ of the respondents perceived health education, counseling services and formation of post counseling support groups to combat stigma and discrimination to be helpful.

Conclusion: Stigma and discrimination affects the rights of People Living with HIV/AIDS (PLWHAs). Such stigmatization and discrimination goes beyond and affects those who care for the PLWHAs, and remains the biggest impediment in the fight against HIV/AIDS in Kibera. Governmental and non-governmental organizations continue to provide key services in the mitigation of stigma and discrimination in Kibera. However, personal testimonies by PLWHAs showed that HIV positive persons still suffer from stigma and discrimination. Approximately $\mathbf{4 3} \%$ of the study population experienced stigma and discrimination.
\end{abstract}

Key Words: Government, non-governmental organizations, stigma and discrimination, HIV/AIDS, Persons Living with HIV/AIDS.

\section{Introduction}

Stigma and discrimination affect the rights of People Living with HIV/AIDS (PLWHAs), societal coping mechanism and caring for the sick and forms the biggest impediment in the fight against HIV/AIDS. The net effect of stigma and discrimination discourages people from declaring their HIV-positive status. Without treatment, care or support, mortality rates would continue to rise and the number of orphaned children will continue to increase. Therefore, reduction of stigma and discrimination would result in reduction in HIV infection rates, and subsequently in reduction in mortality rates (1-3).

This descriptive cross-sectional study assessed the role of governmental and non-governmental organizations in the mitigation of stigma and discrimination against individuals with HIV/AIDS in Kibera, Kenya. It targeted infected and affected people, non-infected community members, and organizations implementing HIV/AIDS programmes.

\section{Methodology}

\section{Study Site}

Kibera is the third largest informal settlement in the world and a settlement for all ethnic groups in Kenya (4). It covers approximately 250 hectares of land with an average population density of 2,000 people per hectare. That density translates into an estimated population of 1 million people (5).

Correspondence to: Margaret Odindo, Community Capacity Building Initiative (CCBI), P.o. Box 1244 - 00606, Nairobi, Kenya. E-mail:mmwanthi@uonbi.ac.ke

${ }^{1}$ Department of Community Health, University of Nairobi, P.O. Box 19676 - 00202, Nairobi, Kenya

\section{Sampling and Data Analysis}

Multi-stage stratified sampling was used to select study households (6). A sample of 1,331 participants were interviewed using qualitative and quantitative data collection instruments; the managers of 50 organizations implementing the programmes in the selected study sites were interviewed, including government and nongovernmental organizations, community based organization and faith based organizations. All the organizations were registered and recognized by the Ministry of Health or Ministry of Social Services. Statistical package for social sciences (SPSS) and Nudist 4 packages were used to analyze quantitative and qualitative data respectively.

\section{Results and Discussion}

A total of 1,331 household participants were interviewed. Overall, $90 \%$ of the respondents were adults, who were either heads of households, spouses or relatives of heads of households. About $2 \%$ of the respondents were the oldest children of the households or household relatives.

\section{Number of people in a household}

About $76 \%$ of the households had up to 10 occupants (mean 3.8). Figure 1 represents the total population in the study households ( $\mathrm{n}=5,024$ from 1,331 households), which is typical of a developing country population structure with a broad base, typifying the preponderance of a youthful population. Age groups between $0-15$ and the elderly ( $>60$ years) are at a greater risk of HIV/AIDS impact than the rest of the population, and also vulnerable to insecurities due to HIV/AIDS epidemic, especially 
when their children and grandchildren succumb to AIDS and leave them with the burden of taking care of the orphans, the children and the youth.

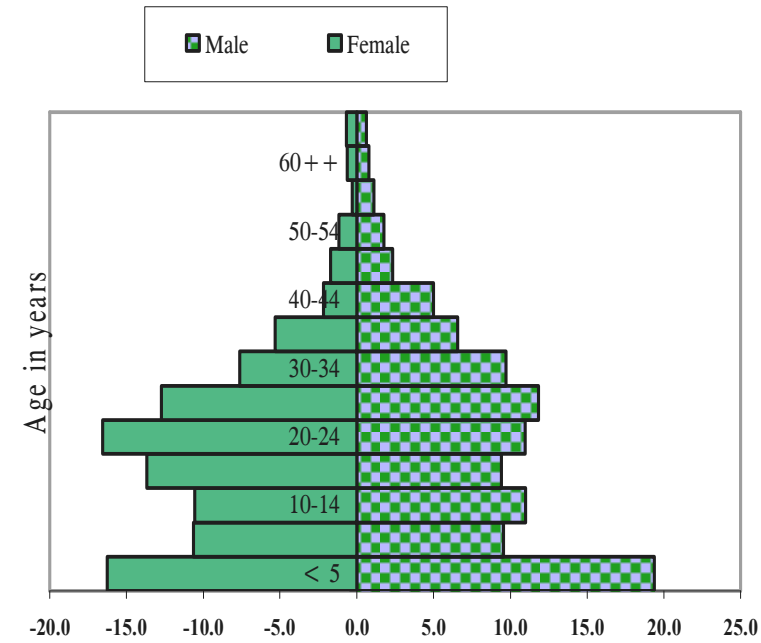

Figure 1: Sex and age distribution of the study population in Kibera $(n=5,024)$

\section{Morbidity}

Over $61 \%$ of the respondents had patients in their households compared to $38.2 \%$ who did not. Incidentally, $34.1 \%(\mathrm{n}=1,427)$ perceived the sick person(s) as having malaria followed by $32.9 \%$ who cited tuberculosis, $29.2 \%$ cited HIV/AIDS while $25.7 \%$ cited rapid weight loss respectively. Among other health conditions mentioned by the respondents were witchcraft, rapid weight loss and hypertension.

\section{Support for the sick}

Among the households with sick people, 55.3\% received some form of assistance for caring for the sick compared to $44.7 \%$ who did not get any support; however, the level of support of the sick differed from village to village. Non governmental organizations and community based organizations (CBOs) provided about $60 \%$ of the care while government and other care givers provided the other proportion of the care (Table 1).

Table 1: Categories of home-based care givers $(n=431)$

\begin{tabular}{llll}
\hline $\begin{array}{l}\text { Category of } \\
\text { givers }\end{array}$ & care & No. of responses & $\begin{array}{l}\text { Percentage } \\
\text { responses }\end{array}$ \\
\hline NGOs & 285 & 49.7 \\
GOK & 118 & 20.6 \\
CBOs & 52 & 9.0 \\
Religious group & 40 & 6.9 \\
Relatives & 30 & 5.2 \\
Other & 23 & 4.0 \\
Neighbours & 21 & 3.7 \\
Not applicable & 5 & 0.9 \\
\hline Total responses & $\mathbf{5 7 4 *}$ & $\mathbf{1 0 0}$ \\
\hline * Due to multiple responses total responses does not equal $\mathrm{n}=431$
\end{tabular}

\section{Type of assistance}

The study established that support from care givers was mostly in the form of medicines $(74.5 \% ; n=529)$, but materials particularly food items and clothing (18.5\%) and money $(4.7 \%)$ were also provided (Figure 2$)$.
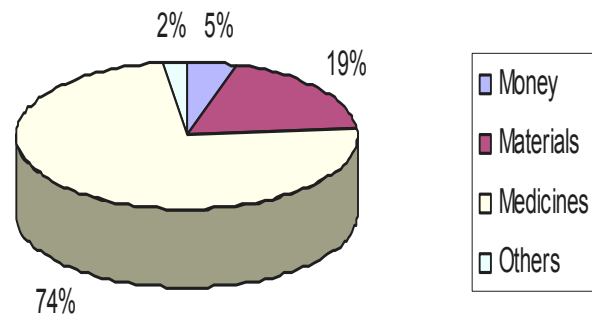

Figure 2: Types of assistance given to communities in Kibera $(n=529)$

\section{Adequacy of support}

Among those who received support, only a quarter thought it was adequate as opposed to over $75 \%(n=431)$ who perceived the support to be inadequate. The kind of additional support sought is presented in Table 2 .

Table 2: Forms of additional support required by community groups $(\mathbf{n}=\mathbf{4 3 1})$

\begin{tabular}{lll}
\hline $\begin{array}{l}\text { Category level } \\
\text { forms of support }\end{array}$ & $\begin{array}{l}\text { No. } \\
\text { responses }\end{array}$ & $\begin{array}{l}\text { of } \\
\text { Percent } \\
\text { responses }\end{array}$ \\
\hline Food and clothing & 169 & 36.7 \\
Medicine & 149 & 31.9 \\
Financial & 95 & 20.6 \\
School fees & 38 & 8.2 \\
Home based care & 8 & 1.7 \\
Permanent jobs & 4 & 0.9 \\
\hline Total responses & $\mathbf{4 6 1}$ & $\mathbf{1 0 0}$ \\
\hline
\end{tabular}

NB: Due to multiple responses total responses does not equal $n=431$

\section{Support Organizations in Kibera}

Anglican, Catholic, Pentecostal Assembly of God (PAG) and the Methodist churches as well as NGOs (both local and international) were cited as the major supporters while CBOs and self help groups and government agencies were rated second. Other NGOs mentioned by the respondents included African Medical Research Foundation (AMREF), Medicine san Frontiers (MSF), Pathfinder International, Kibera Community Self Help Programme (KICOSHEP) and Action Aid. The government through Kenyatta National Hospital (K.N.H) 
and Kenya Medical Research Institute (KEMRI) were cited as the least supporters.

\section{HIV/AIDS Organizations}

Ninety percent $(90 \%)$ of the respondents were aware of an organization implementing HIV/AIDS prevention and control programmes in their communities, compared to $8.9 \%$ who did not know. These statistics were in agreement with the awareness levels of the HIV/AIDS scourge indicated by other studies such as the Kenya Demographic and Health Survey (2003) and the 1999 population census. Awareness levels of organizations implementing HIV/AIDS programmes by village are presented in Figure 3.

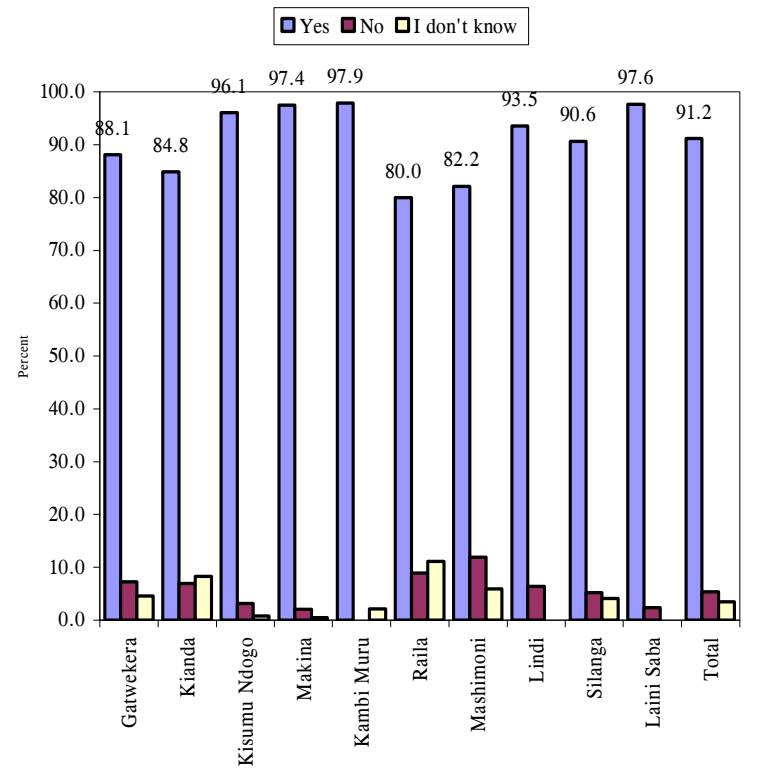

Figure 3: Awareness of organization implementing HIV/AIDS programmes in various villages in Kibera $(\mathrm{n}=1,331)$

When further asked to list the organizations that provided HIV/AIDS prevention and control programmes, KICOSHEP, MSF, AMREF were dominantly mentioned by $41 \%, 40 \%$ and $32.8 \%$, respectively. Additionally, Centre for Disease Control (CDC), Ushirika, Kawanga, PAG Church and Lea Toto were the least listed organization that offered HIV/AIDS prevention and control programmes.

Raising awareness, guiding and counseling were the main services provided by the HIV/AIDS related organizations in Kibera. These two services were mentioned by $(20.2 \%),(n=448)$ of the respondents and $(19 \%)$ respectively. Other services provided were testing (17.1\%); treatment (14\%); advocacy (13.7\%) home based care $(10.2 \%)$; assistance to orphans $(4.4 \%)$; legal $(0.3 \%)$ and others $(0.4 \%)$.
Stigma and Discrimination versus Satisfaction with Stigma and Discrimination Services

Majority (80\%) of the respondents indicated that HIV/AIDS organizations had programmes that address issues of stigma and discrimination in their prevention and control programmes as opposed to $17.4 \%$ that were perceived not to have had the programme.

\section{Satisfaction with Stigma and Discrimination Services}

About $90 \%$ of the respondents perceived the health education, counseling services and formation of post counseling support groups to combat stigma and discrimination to be very helpful, while $6 \%$ perceived them to be somewhat helpful. A negligible percent $(3 \%)$ perceived that they were not adequate and not helpful at all.

Stigma and discrimination services were provided daily as reported by $40.6 \%$ of the respondents followed by $34.3 \%$ who indicated that they were provided on monthly basis while $22.2 \%$ indicated that they were conducted on weekly basis.

\section{Care Providers}

Three hundred and seventy-eight (378) of the 511 care givers interviewed were females, compared to 133 males. Significantly, $(\mathrm{p}=0.01)$ a higher number of females provided care and support to people living with HIV/AIDS within the families. Among the female providers it was reported that mothers, wives, sisters and grandmothers provided care in the proportions $32.3 \%, 10.1 \%, 7.3 \%$ and $1.1 \%$ respectively.

\section{Gender, Age and Education Distribution of the Care Giver}

Out of the 511 care givers, most of them were relatively young. About one third (35.7\%) were in a stratum of 26-49 years. The least proportion represented $7.6 \%$ and was over 50 years. Furthermore, $74 \%$ of the respondents were females while $26 \%$ were males therefore it sensitize women on the issues of stigma and discrimination (7). Approximately, $60 \%$ of the care givers had attained primary education and $29.8 \%$ had attained secondary education. Those who had no formal training represented $7.8 \%$ while the least $(5.1 \%)$ percentage had attained post secondary training.

\section{Stigma and Discrimination Among the Population}

The study established that stigma and discrimination was common in Kibera. More than $43 \%$ of the study population responded that they had experienced stigma and discrimination as opposed to $57 \%$ who had not experienced stigma and discrimination.

\section{Stigma Among People Living with HIV/AIDS}

Among the PLWHA, there was a high level of stigma 
and discrimination in almost all villages where the study was conducted; when people living with HIV/AIDS were asked if they are discriminated, $75 \%$ were affirmative as compared to about $25 \%$ who indicated otherwise.

\section{PLWHA Discriminators}

Friends, peers and workmates represented $46.4 \%$ of discriminators of People Living with HIV/AIDS while family members and spouses $(27.3 \%)$ and the community, including the faith community $(10.9 \%)$ were the other leading abusers of PLWHA (Figure 4). Other discriminators included brief contacts, visitors and persons from outside the immediate community (15.4\%).
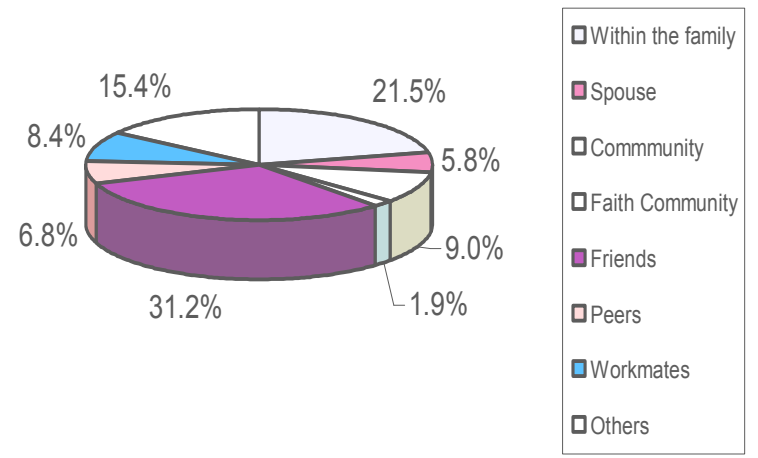

Figure 4: Proportion of sources of discrimination for PLWHAs in Kibera $(\mathrm{n}=331)$

\section{Forms of Discrimination}

Discrimination because of HIV/AIDS was mainly in the form of segregation and separation. It was reported by about $64 \%$ that they were confined to particular sitting area or sleeping area, or using different eating utensils.

\section{Other Challenges for PLWHA}

The respondents noted that PLWHAs in Kibera face many challenges in their daily lives. Apart from stigma and discrimination, they also face rejection (40.7\%), inadequate food $(34.3 \%)$, financial inadequacies, lack of proper housing, and loneliness. Inadequacy was due to unavailability rather than denial by relatives or friends.

\section{Conclusion and Recommendations}

Most $(75 \%)$ of people living with HIV/AIDS had been discriminated against in Kibera. When the respondents were asked who directed discrimination against them, friends led the list of discriminators of People Living with HIV/AIDS, and were cited by $54 \%$ of the respondents. Family members (37\%) and community (15.8\%) were the other leading abusers of PLWHA. In focus group discussions, it emerged that one church in Kibera had separate seating for the infected persons. However, other churches reaffirmed that a response to the challenges of HIV/AIDS was a top priority on the ecumenical agenda.

Although, the study established that the number of care givers was low, community members concurred that support in home based care should be promoted as it plays an important role in reduction of stigma and discrimination. In families where home based care was practiced, spouses and family members supported PLWHAs. Indeed, in such families, PLWHAs openly declared their status.

On the other hand, denial among the patients and relatives on the illness of HIV/AIDS was found to be high. HIV/AIDS ranked as the third most commonly perceived condition for those homes with patients, while malaria toped the list, followed by tuberculosis, then rapid weight loss. If it were considered that tuberculosis and rapid weight loss were closely associated with HIVAIDS, then the true level of HIV/AIDS infection in Kibera would likely be higher than shown during the study.

There were policies and strategies that supported training of care givers at the home level but there were no strategies for monitoring the implementation of these polices. There is therefore need for the government to design strategies to monitor and supervise the implementation of these polices.

Out of the 60 organizations visited, only 45 were traced to a physical location. The rest did not have a physical presence in Kibera. There is need for the government to develop an inventory for the organizations in Kibera, define their role in order to avoid duplication and promote networking to enable all the sick members of community to access the care and support programme in view of reduction of stigma and discrimination on HIV/AIDS.

About $90 \%$ of the respondents perceived health education; counseling services and formation of postcounseling support groups as effective means of combating stigma and discrimination similar views have been expressed by other researchers (8). Kenya has policies on stigma and discrimination but implementation and monitoring of these policies leaves a lot to be desired. Among the organizations interviewed, only $2 \%$ had a workplace programme. Incidentally, employee orientation programmes should include issues of stigma and discrimination and people's right with respect to HIV/AIDS. This will go along way towards ensuring that stigma is addressed in places such as Kibera.

Stigma and discrimination discourage people from disclosing their HIV positive status until it has progressed into full blown AIDS. The community will not change their attitude if they are not getting the right education. There is need to conduct training needs assessment in Kibera slums on matters of stigma and discrimination on HIV/AIDS. The needs assessment data will form the basis for development of strategy for reduction of stigma and discrimination.

The key areas not included in the study but warranting further investigation, include: systems of governance, cultural differences and the overall socio-economic status of the people. Information obtained should be used for the 
purpose of future planning of intervention programmes.

\section{Acknowledgement}

We are grateful to Dr.Joshua Mainga for his support throughout the study. We are also indebted to Mr. Collins Aluda for his technical assistance during data analysis, Ms Regina Juma and Ms Jemimah Mbola for working tirelessly in the field. Special thanks to the Office of the President for the permission granted to us to conduct research in Kibera. We are also indebted to chief and sub-chief of Kibera sub-location and community health workers for their assistance in giving relevant information and facilitating identification of PLWHAs and caregivers. We cannot forget to thank the two village elders Mr. Joseph Osir Okoth and Mr.Nassir Musa who worked with the research assistants throughout data collection period despite the heavy rains. Special thanks go to the heads of the organizations, project supervisors, care givers, PLWHAs and all the residents who spared their precious time to answer the questionnaire and allowed the research team to visit their homes.

Special thanks go to Community Capacity Building Initiative (CCBI) staff, particularly the Director, Dr. Maurice Odindo for his advice and technical assistance throughout the research.

\section{References}

1. Fredriksson $\mathrm{J}$ and Kanabus A. HIV and AIDS: Stigma and discrimination. http://www.avert.org/aidsstigma.htm.

2. Link B.G., Phelan J. Conceptualizing stigma. Ann Rev.Social 2001, .27: 363 385

3. McIntyre B. HIV/AIDS Stigma and Discrimination, 10th August 2006. http: www.thezambian.com/aids/stigma.

4. Ndeti Y. A brief History of Kibera, 2003, http://en.wikipedia.org/wiki/Kibera. 5. Kenya Water for Health Organization. KWAH/SANDEC-SODIS in Kenya 2005, htt://www.kwaho.org/pd-sodis.html.

6. Mugenda $O M \&$ Mugenda A G. Research Methods Quantitative and Qualitative Approaches. African Centre for Technology Studies 1999. Nairobi.

. Gathirua GW and Murage JM.. Overcoming barriers to HIV/AIDS stigma and discrimination among women in Kenya, American Public Health Association 133rd Annual Meeting \& Exposition 2005: New Orleans. LA.

8. Brown L, Macintyre K, Trujillo L. Interventions to Reduce HIV/AIDS Stigma What have We Learned? AIDS Education and Prevention 2003, 15 (1): 49-69.

Received 23 October 2007; Revised 20 February 2008; Accepted 25 February 2008 